\title{
Quality of life after prostate cancer treatments in patients comparable at baseline
}

\author{
J J van Tol-Geerdink ${ }^{*}, 1$, J W H Leer ${ }^{1}$, I M van Oort ${ }^{2}$, E J N T van Lin ${ }^{1}$, P C Weijerman ${ }^{3}$, H Vergunst ${ }^{4}$, J A Witjes ${ }^{2}$ \\ and P F M Stalmeier ${ }^{5}$ \\ ${ }^{1}$ Department of Radiation Oncology, Radboud University Medical Centre, PO Box 9101, Nijmegen, The Netherlands; \\ ${ }^{2}$ Department of Urology, Radboud University Medical Centre, PO Box 9101, Nijmegen, The Netherlands; ${ }^{3}$ Department of \\ Urology, Rijnstate Hospital, PO Box 9555, Arnhem, The Netherlands; ${ }^{4}$ Department of Urology, Canisius Wilhelmina Hospital, \\ PO Box 9015, Nijmegen, The Netherlands and ${ }^{5}$ Department of Health Evidence, Radboud University Medical Centre, \\ PO Box 9101, Nijmegen, The Netherlands
}

Background: Previous studies on the effects of different prostate cancer treatments on quality of life, were confounded because patients were not comparable. This study examined treatment effects in more comparable groups.

Methods: From 2008-2011, 240 patients with localised prostate cancer were selected to be eligible for both radical prostatectomy (RP) and external beam radiotherapy (EBRT). Brachytherapy (BT) was a third option for some. Health-related quality of life was measured by expanded prostate cancer index composite (EPIC) up to 12 months after treatment.

Results: In the sexual domain, RP led to worse summary scores $(P<0.001)$ and more often to a clinically relevant deterioration from baseline than BT and EBRT (79\%, 33\%, 34\%, respectively). In the urinary domain, RP also led to worse summary scores $(P=0.014)$, and more deterioration from baseline $(41 \%, 12 \%, 19 \%$, respectively). Only on the irritative/obstructive urinary scale, more BT patients (40\%) showed a relevant deterioration than RP (17\%) and EBRT patients (11\%). In the bowel domain, the treatment effects did not differ.

Conclusion: This study provides a more unbiased comparison of treatment effects, as men were more comparable at baseline. Our results suggest that, for quality of life, radiotherapy is as least as good an option as RP for treating localised prostate cancer.

Many studies have focused on the effect of prostate cancer treatments on quality of life. The most common treatments for localised prostate cancer are prostatectomy and radiotherapy (interstitial or external). Differences in associated healthrelated quality of life (HR-QOL) have been reported. Radical prostatectomy (RP) causes more urinary incontinence and erectile dysfunction, whereas radiotherapy causes more irritative symptoms and bowel problems, as reported in reviews (Penson, 2007).

To date, however, this comparison has been confounded by the fact that the patients in the different treatment groups were not comparable. In most studies, for example, the surgery patients were younger (Madalinska et al, 2001; Wei et al, 2002; Talcott et al, 2003; Korfage et al, 2005; Ferrer et al, 2008; Smith et al, 2009; Huang et al, 2010), had less aggressive tumours (Madalinska et al, 2001; Wei et al, 2002; Korfage et al, 2005; Ferrer et al, 2008; Huang et al, 2010) and better pre-treatment functioning (Talcott et al, 2003; Ferrer et al, 2008; Huang et al, 2010) than the patients receiving external beam radiotherapy (EBRT). Patients characteristics differed because they were used as selection criteria for treatment choice. This is problematic, because, for example, age at diagnosis and pre-treatment functioning are significant predictors of HR-QOL in all domains (Stanford et al, 2000; Talcott et al, 2003; 
Huang et al, 2010). Reducing the baseline differences between the patients would yield a more unbiased comparison of the treatment effects.

As randomisation to treatment groups is not feasible, see, for example, the attempted RCT by Crook et al (Crook et al, 2011), we chose a different approach to reduce the differences. In the present study, only patients who were eligible for both prostatectomy and EBRT were asked to participate. We used this improved design, to obtain patients that were more comparable at baseline with regard to patient and tumour characteristics. In this more homogeneous population, this study aims to compare treatment effects on HRQOL scores and their clinically relevant changes.

\section{MATERIALS AND METHODS}

Patients. Between March 2008 and February 2011, patients with primary localised prostate cancer ( $1-3 \mathrm{aN} 0 \mathrm{M} 0)$, intending to be treated and eligible for both radiotherapy and RP, were asked to participate in this prospective study. Exclusion criteria were contra-indication for surgery (based on e.g., cardiovascular problems) or external radiotherapy (based on e.g., Crohn's disease), mental or cognitive problems as assessed by the physician, inadequate knowledge of the Dutch language, which might interfere with filling out the questionnaires, or a preference for active surveillance.

Radical prostatectomy and EBRT were offered to all patients. Some patients were, in addition, eligible for brachytherapy (BT). To those patients, BT was offered, as a third option. Exclusion criteria for BT were a small or large prostate volume $(<20 \mathrm{cc}$ or $>50 \mathrm{cc})$, PSA $>15$, Gleason $>7$ and/or severe urinary symptoms (requiring medication or, if available, IPSS $>12$ and/or $Q_{\max }<15 \mathrm{ml} \mathrm{s}^{-1}$ ).

Recruitment took place in three training hospitals in the Netherlands, that is, the Radboud University Nijmegen Medical Centre, the Canisius Wilhelmina Hospital in Nijmegen, and the Rijnstate Hospital in Arnhem. The latter two are large nonacademic centres. The study was approved by the research ethics committees of these hospitals.

The study took place within a randomised-controlled trial of a decision aid. One group only discussed the treatment choice with their specialist, the other group had an additional consult with the researcher, during which the pros and cons of the different treatment options were discussed by means of a decision aid. No effect of the decision aid on HR-QOL was found. The study was described previously in more detail (van Tol-Geerdink et al, 2013).

Measures. Data were collected on several variables that were expected to affect the HR-QOL. The assessments were at baseline, that is, pre-treatment and at 12 months after treatment. For EBRT, this was defined as 12 months after the last radiotherapy session.

Patients' demographic and medical characteristics. Self-report data were collected on demographic variables (age, education). Tumour characteristics ( $T$ status, pre-treatment PSA value and Gleason score) were extracted from the medical records.

Health-related quality of life. HR-QOL was assessed by means of the EPIC (Wei et al, 2000). This prostate-specific instrument includes questions on function (do you have certain symptoms) and on bother (to what extent are the symptoms a problem for you) in the urinary, bowel, sexual and hormonal domain. It provides three scales per domain, a function score, a bother score and a summary score, ranging from $0-100$, with higher scores reflecting better functioning. The expected effect on urinary functioning differs between the treatments, with incontinence related more to prostatectomy and irritative/obstructive symptoms related more to radiotherapy. Therefore, we also assessed the incontinence and irritative/obstructive subscales, yielding 11 EPIC scale scores in total.

In addition to scale scores, we examined scores on distinctive items from each domain separately. These single items were added because they are believed to be more illustrative and informative than scale scores to some clinicians. For the urinary domain, we used the item 'How many pads or adult diapers per day did you usually use to control leakage during the last 4 weeks?', with answers dichotomised to 'none' vs 'one or more pads per day' (Miller et al, 2005). This strict definition of incontinence was chosen, as recommended, because quality of life was found to be higher for none than for one or more pads per day (Liss et al, 2010). For the bowel domain, we used the item 'How often have you had stools (bowel movements) that were loose or liquid during the last 4 weeks?', with answers dichotomised to 'no/seldom loose stool' vs 'at least half of the time loose stool' (Madalinska et al, 2001). For the sexual domain, we used 'How would you describe the usual quality of your erections during the last 4 weeks?', with answers dichotomised to 'firm enough for intercourse' vs 'not firm enough for intercourse' (Stanford et al, 2000).

Analyses. Our primary research question was to compare treatment effects on HR-QOL. The patients' quality of life was assessed with the EPIC scales ranging from 0-100. Unadjusted scores are presented for all scales. The effect of treatment was analysed in analyses of variance. These ANOVAs were corrected for the corresponding baseline scores. For example, differences between RP and BT on the urinary function score at 12 months were corrected for the baseline urinary function scores. In addition, variables were considered as possible confounding factors if they differed at baseline between the treatment groups $(P<0.15)$, and were related to HR-QOL. None of the demographic or medical variables, however, met these criteria. Therefore, analyses were not corrected for such confounders, and all presented means are unadjusted.

The scores were also expressed as the proportion of patients with a clinically significant deterioration from baseline. This was defined as a minimally important difference (MID) of more than half a s.d. (Norman et al, 2003). The s.d. values in this study for urinary, bowel and sexual summary scores were 14, 7 and 22, respectively, yielding MIDs of 7, 3.5 and 11, respectively. The urinary incontinence and irritative/obstructive subscales had standard deviations of 28 and 10, respectively, yielding MIDs of 14 and 5, respectively. These MID values correspond well with those reported by others (Morton et al, 2011). The percentage of patients with a clinically relevant deterioration from baseline was analysed by $\chi^{2}$-tests.

From the urinary, bowel and sexual domain, a single representative item was selected: the need for urinary pads, the frequency of loose stool and the firmness of the erections, respectively. The scores on these items were dichotomised (see above) and analysed by treatment, using the $\chi^{2}$-test. In addition, a separate analysis was done on patients with good baseline functioning on the three selected single items. The proportion of patients that changed to poorer outcome at 12 months after treatment were analysed by $\chi^{2}$-tests.

Baseline differences between the treatment groups were examined using $t$-tests for continuous variables and using $\chi^{2}$-tests for dichotomous or ordinal variables. In case of missing data, EPIC scale values were calculated only if at least $80 \%$ of the items were filled out, by imputing the mean of the remaining items.

\section{RESULTS}

Patients. In total, 307 patients were asked to participate in the study. Of these patients, 36 declined (12\%) and 271 gave informed 
consent (88\%). Of these 271 patients, 31 were excluded because additional screening revealed other health problems $(n=14)$ or because they chose active surveillance after all $(n=17)$. This yielded a total of 240 patients included in this study. Of the 240, a total of $36(15 \%)$ were lost during follow-up up to 12 months after treatment. Those 36 patients did not differ significantly in age, education or tumour characteristics from those with complete follow-up. Reasons for drop out are given in Figure 1. The drop out was comparable in the RP, BT and EBRT groups (16\%, $11 \%$ and $14 \%$, respectively). For the sexual domain, follow-up data were missing for an additional eight patients, due to their reluctance to answer questions on sexual functioning.

Treatments received. The treatments received were RP $(n=170)$, BT $(n=28)$ and EBRT $(n=42)$. Prostatectomy was performed by robot-assisted laparoscopic prostatectomy (60\%), laparoscopic procedure without robot $(25 \%)$ or open surgery (15\%). The procedures were either nerve sparing $(81 \%)$ or non-nerve sparing (19\%). None of the surgical patients received postoperative radiotherapy in the year after treatment. Brachytherapy was performed in the hospital in Arnhem with low-dose seed implants. External beam radiotherapy was given by IMRT at an (equivalent) dose of $78 \mathrm{~Gy}$. All but seven EBRT patients were irradiated at the Radboud University Nijmegen, using an endorectal balloon with the intention to limit rectal toxicity, and five EBRT patients received additional androgen deprivation therapy.

Baseline differences. At baseline, no significant differences between patients eventually receiving RP, BT or EBRT were found for patient characteristics nor for general health assessment (Table 1). In general, the EPIC scores did not differ significantly either, except for better baseline scores on the urinary domain in the group receiving BT (Table 2). The latter was expected because urinary symptoms are an exclusion criterion for BT. Analyses were corrected by including the baseline scores as covariates.

Health-related quality of life effects of treatment received. Table 3 gives an overview of the unadjusted EPIC scores at 12 months after treatment for RP, BT and EBRT. The statistical tests

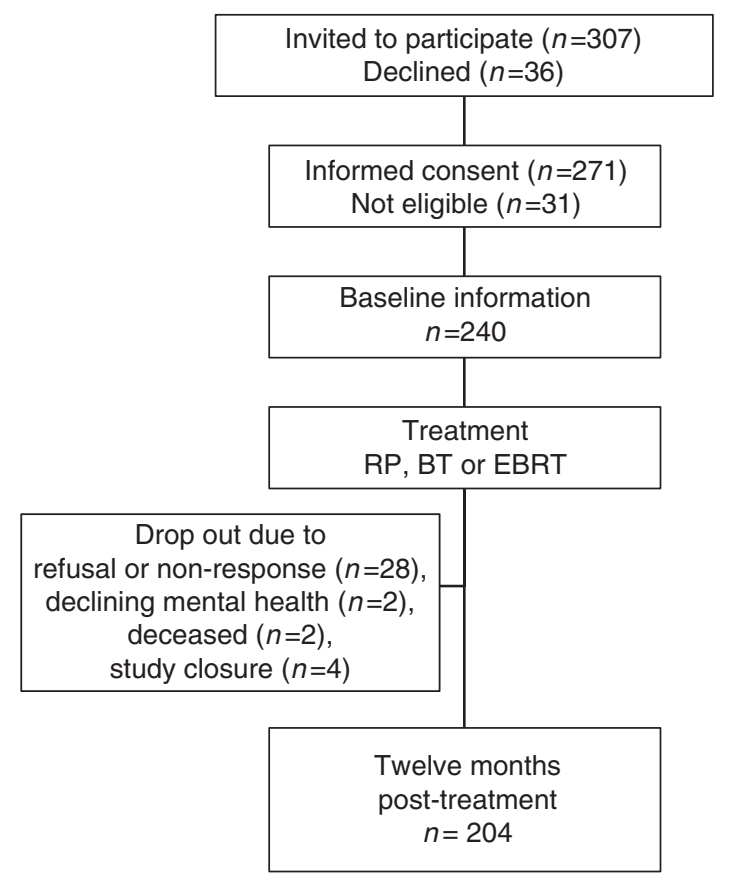

Figure 1. Patient flow. to compare treatments were corrected for the patients' baseline EPIC scores. Significant differences were only found between RP and the other two treatments (BT and EBRT), and only in the urinary and sexual domain. Radical prostatectomy gave worse

Table 1. Baseline patients characteristics by treatment: radical prostatectomy (RP), brachytherapy (BT) or external beam radiotherapy (EBRT)

\begin{tabular}{|c|c|c|c|c|}
\hline & $\begin{array}{c}\text { RP } \\
N=170\end{array}$ & $\begin{array}{c}\text { BT } \\
N=28\end{array}$ & $\begin{array}{l}\text { EBRT } \\
\mathbf{N}=42\end{array}$ & $\boldsymbol{P}$-value \\
\hline \multicolumn{5}{|l|}{ Demographic } \\
\hline Age in yearsr (mean (s.d.)) & $64(5)$ & $64(5)$ & $65(6)$ & 0.44 \\
\hline Education: college or more (\%) & $33 \%$ & $30 \%$ & $31 \%$ & 0.94 \\
\hline Living with partner (\%) & $89 \%$ & $89 \%$ & $83 \%$ & 0.56 \\
\hline \multicolumn{5}{|l|}{ Tumour characteristics } \\
\hline T1-2 (\%) & $91 \%$ & $100 \%$ & $84 \%$ & 0.13 \\
\hline Gleason $\leqslant 7(\%)$ & $97 \%$ & $100 \%$ & $91 \%$ & 0.15 \\
\hline$P S A \leqslant 20(\%)$ & $94 \%$ & $100 \%$ & $91 \%$ & 0.27 \\
\hline $\begin{array}{l}\text { General health score } \\
\text { (mean (s.d.)) }\end{array}$ & $7.9(1.4)$ & $7.9(1.6)$ & $7.8(1.4)$ & 0.89 \\
\hline \multicolumn{5}{|c|}{$\begin{array}{l}\text { Abbreviation: PSA = prostate-specific antigen. } \\
{ }^{a} \text { Self-rated general health on scale from } 1 \text { (poor health) to } 10 \text { (excellent health). }\end{array}$} \\
\hline
\end{tabular}

Table 2. Baseline EPIC ${ }^{a}$ scores by treatment received: radical prostatectomy (RP), brachytherapy (BT) or external beam radiotherapy (EBRT)

\begin{tabular}{|l|c|c|c|c|}
\hline \multicolumn{1}{|c|}{} & RP & BT & EBRT & \\
& $\boldsymbol{N}=160$ & $\boldsymbol{N}=28$ & $\boldsymbol{N}=42$ & \\
& mean & mean & mean & \multirow{2}{*}{ mealue } \\
& (s.d.) & (s.d.) & (s.d.) & P-valu
\end{tabular}

\begin{tabular}{|l|l|l|l|l|}
\hline Urinary scales \\
\hline Summary score & $87(12)^{\mathbf{b}}$ & $93(8)^{\mathbf{b}, \mathbf{c}}$ & $85(13)^{\mathbf{c}}$ & 0.02 \\
Function score & $93(11)$ & $97(7)$ & $91(14)$ & 0.09 \\
Bother score & $83(15)^{\mathbf{b}}$ & $91(9)^{\mathbf{b}, \mathbf{c}}$ & $82(15)^{\mathbf{c}}$ & 0.02 \\
Incontinence scale $_{\text {Irritative-Obstructive scale }}$ & $93(16)$ & $96(12)$ & $92(14)$ & 0.43 \\
\hline & $85(13)^{\mathbf{b}}$ & $92(7)^{\mathbf{b}, \mathbf{c}}$ & $82(14)^{\mathbf{c}}$ & 0.01
\end{tabular}

Bowel scales

\begin{tabular}{|l|l|l|l|l|}
\hline Summary score & $96(7)$ & $98(3)$ & $95(8)$ & 0.21 \\
Function score & $95(8)$ & $97(4)$ & $95(8)$ & 0.29 \\
Bother score & $97(6)$ & $99(3)$ & $96(8)$ & 0.16
\end{tabular}

Sexual scales

\begin{tabular}{|l|l|l|l|l}
\hline Summary score & $60(21)$ & $56(23)$ & $58(24)$ & 0.66 \\
Function score & $52(21)$ & $50(25)$ & $49(26)$ & 0.70 \\
Bother score & $78(25)$ & $70(26)$ & $78(28)$ & 0.33
\end{tabular}

Single items

'No/seldom loose stool'

'Erections firm enough for

$99 \% \quad 96 \%$

$96 \%$

$93 \%$

$91 \% \quad 100 \%$

$90 \%$

0.10 intercourse'

The single items were expressed as $\%$ of patients with that answer and were analysed by $\chi^{2}$-tests.

a All EPIC scales range from 0-100, with higher scores representing better functioning.

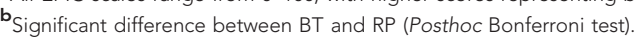

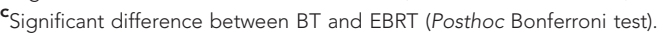


Table 3. Unadjusted EPIC a scores at 12 months after treatment by treatment received: radical prostatectomy (RP), brachytherapy (BT) or external beam radiotherapy (EBRT)

\begin{tabular}{|c|c|c|c|c|}
\hline & $\begin{array}{c}R P \\
N=143 \\
\text { mean } \\
\text { (s.d.) }\end{array}$ & $\begin{array}{c}\text { BT } \\
N=25 \\
\text { mean } \\
\text { (s.d.) }\end{array}$ & $\begin{array}{c}\text { EBRT } \\
\mathbf{N}=36 \\
\text { mean } \\
\text { (s.d.) }\end{array}$ & $\boldsymbol{P}$-value \\
\hline \multicolumn{5}{|l|}{ Urinary scales } \\
\hline $\begin{array}{l}\text { Summary score } \\
\text { Function score } \\
\text { Bother score } \\
\text { Incontinence scale } \\
\text { Irritative-Obstructive scale }\end{array}$ & $\begin{array}{l}82(15) \\
81(18)^{b, c} \\
83(14) \\
69(28)^{b, c} \\
91(9)\end{array}$ & $\begin{array}{l}90(10) \\
96(10)^{\mathrm{b}} \\
87(12) \\
95(16)^{\mathrm{b}} \\
88(10)\end{array}$ & $\begin{array}{l}88(13) \\
91(13)^{c} \\
85(14) \\
86(19)^{c} \\
89(11)\end{array}$ & $\begin{array}{c}0.014 \\
<0.001 \\
0.58 \\
<0.001 \\
0.22\end{array}$ \\
\hline \multicolumn{5}{|l|}{ Bowel scales } \\
\hline $\begin{array}{l}\text { Summary score } \\
\text { Function score } \\
\text { Bother score }\end{array}$ & $\begin{array}{l}95(7) \\
94(8) \\
96(7)\end{array}$ & $\begin{array}{l}95(6) \\
94(6) \\
96(7)\end{array}$ & $\begin{array}{l}94(10) \\
92(12) \\
94(11)\end{array}$ & $\begin{array}{l}0.44 \\
0.43 \\
0.28\end{array}$ \\
\hline \multicolumn{5}{|l|}{ Sexual scales } \\
\hline $\begin{array}{l}\text { Summary score } \\
\text { Function score } \\
\text { Bother score }\end{array}$ & $\begin{array}{l}29(17)^{b, c} \\
22(17)^{b, c} \\
43(26)^{b, c}\end{array}$ & $\begin{array}{l}46(23)^{\mathbf{b}} \\
39(23)^{\mathrm{b}} \\
62(28)^{\mathrm{b}}\end{array}$ & $\begin{array}{l}52(26)^{c} \\
43(27)^{c} \\
73(32)^{c}\end{array}$ & $\begin{array}{l}<0.001 \\
<0.001 \\
<0.001\end{array}$ \\
\hline \multicolumn{5}{|l|}{ Single items } \\
\hline $\begin{array}{l}\text { 'No urinary pads required' } \\
\text { 'No/seldom loose stool' } \\
\text { 'Erections firm enough for } \\
\text { intercourse' }\end{array}$ & $\begin{array}{c}61 \% \\
92 \% \\
8 \%\end{array}$ & $\begin{array}{l}96 \% \\
96 \% \\
36 \%\end{array}$ & $\begin{array}{l}89 \% \\
92 \% \\
39 \%\end{array}$ & $\begin{array}{l}<0.001 \\
0.74 \\
<0.001\end{array}$ \\
\hline \multicolumn{5}{|c|}{$\begin{array}{l}\text { The } P \text {-values are based on analysis of variance corrected for baseline scores. The single } \\
\text { items were expressed as \% of patients with that answer and were analysed by } \chi^{2} \text {-tests. } \\
\text { a All EPIC scales range from 0-100, with higher scores representing better functioning. } \text { b }_{\text {Significant difference between RP and BT corrected for baseline scores (Posthoc }} \\
\text { Bonferroni test). } \\
{ }_{\text {Significant difference between RP and EBRT corrected for baseline scores (Posthoc }} \\
\text { Bonferroni test). }\end{array}$} \\
\hline
\end{tabular}

outcomes than BT and EBRT in both domains. With regard to the scales in the bowel domain, no differences were found between the treatments.

Analysing single items from the different domains yielded similar results. For example, the proportion of patients not requiring urinary pads was comparable at baseline (Table 2) for $\mathrm{RP}, \mathrm{BT}$ and EBRT, but differed at 12 months $(P<0.001)$ (Table 3 ). Similarly, the proportion of patients reporting erections firm enough for intercourse was comparable at baseline (Table 2), but differed at follow-up $(P<0.001)$ (Table 3$)$. The frequency of loose stool was comparable between the treatments at baseline (Table 2) and remained so at follow-up (Table 3).

Table 4 shows the proportions of patients experiencing a clinically relevant deterioration in EPIC scores, from baseline to 12 months after treatment. These proportions were again significantly affected by treatment received for the urinary and sexual domains and not for the bowel domain. After RP, more patients deteriorated on EPIC scores.

In Table 5, the results of patients with good baseline scores on specific items are presented. For patients who did not require urinary pads at baseline, the risk of requiring pads at 1 year after treatment was higher after RP (38\%) than after BT $(0 \%)$ or EBRT $(6 \%, P<.001)$. Similarly, for patients with erections firm enough for intercourse at baseline, the risk of having insufficient erectile functions at 1 year after treatment was higher after RP (89\%) than after BT $(57 \%)$ or EBRT $(33 \%, P<0.001)$. The risk of having loose or liquid stool was not affected by treatment received.
Table 4. Percentage of patients with a clinically relevant deterioration in EPIC scores at 12 months after treatment compared with their baseline scores, defined as a decrease of $\geqslant$ half a s.d.

\begin{tabular}{|c|c|c|c|c|}
\hline & $\begin{array}{c}\mathrm{RP} \\
N=142\end{array}$ & $\begin{array}{c}\text { BT } \\
N=25\end{array}$ & $\begin{array}{l}\text { EBRT } \\
\mathbf{N}=36\end{array}$ & $\boldsymbol{P}$-value \\
\hline \multicolumn{5}{|l|}{ Urinary } \\
\hline $\begin{array}{l}\text { Deterioration in summary } \\
\text { score }\end{array}$ & $41 \%$ & $12 \%$ & $19 \%$ & 0.003 \\
\hline $\begin{array}{l}\text { Deterioration in function } \\
\text { score }\end{array}$ & $42 \%$ & $12 \%$ & $19 \%$ & 0.002 \\
\hline Deterioration in bother score & $30 \%$ & $40 \%$ & $25 \%$ & 0.45 \\
\hline $\begin{array}{l}\text { Deterioration on } \\
\text { incontinence scale }\end{array}$ & $55 \%$ & $12 \%$ & $29 \%$ & $<0.001$ \\
\hline $\begin{array}{l}\text { Deterioration on irritative/ } \\
\text { obstructive scale }\end{array}$ & $17 \%$ & $40 \%$ & $11 \%$ & 0.012 \\
\hline \multicolumn{5}{|l|}{ Bowel } \\
\hline $\begin{array}{l}\text { Deterioration in summary } \\
\text { score }\end{array}$ & $21 \%$ & $26 \%$ & $29 \%$ & 0.63 \\
\hline $\begin{array}{l}\text { Deterioration in function } \\
\text { score }\end{array}$ & $17 \%$ & $16 \%$ & $25 \%$ & 0.52 \\
\hline Deterioration in bother score & $14 \%$ & $22 \%$ & $26 \%$ & 0.19 \\
\hline \multicolumn{5}{|l|}{ Sexual } \\
\hline $\begin{array}{l}\text { Deterioration in sexual } \\
\text { summary score }\end{array}$ & $79 \%$ & $33 \%$ & $34 \%$ & $<0.001$ \\
\hline $\begin{array}{l}\text { Deterioration in function } \\
\text { score }\end{array}$ & $76 \%$ & $36 \%$ & $43 \%$ & $<0.001$ \\
\hline Deterioration in bother score & $74 \%$ & $33 \%$ & $33 \%$ & $<0.001$ \\
\hline
\end{tabular}

Table 5. Percentage of patients with good baseline functioning that changed to poorer functioning at 12 months after treatment for a given item in each domain

\begin{tabular}{|l|c|c|c|l|}
\hline & RP & BT & EBRT & \\
& N & N & N & \\
& $(\%)$ & $(\%)$ & $(\%)$ & $P$-value \\
\hline
\end{tabular}

Urinary

\begin{tabular}{l|c|c|c|c|}
\hline $\begin{array}{l}\text { From 'no urinary pads' at } \\
\text { baseline }(N=196)\end{array}$ & $N=139$ & $N=24$ & $N=33$ & \\
$\begin{array}{l}\text { to 'one or more per day' } \\
\text { at } 12 \text { months }\end{array}$ & $N=53$ & $N=0$ & $N=2$ & $<0.001$ \\
\hline
\end{tabular}

\section{Bowel}

From 'no/seldom loose stool' at baseline $(N=115)$

to 'at least half of the time loose stool'

\begin{tabular}{l|l|l|l}
$N=81$ & $N=14$ & $N=20$ & \\
$N=3$ & $N=0$ & $N=1$ & 0.72 \\
$(4 \%)$ & $(0 \%)$ & $(5 \%)$ &
\end{tabular}

\section{Sexual}

From 'erections firm enough

for intercourse' $(N=107)$

to 'not firm enough'

\begin{tabular}{|l|l|l|l|}
$N=75$ & $N=14$ & $N=18$ & \\
$N=67$ & $N=8$ & $N=6$ & $<0.001$ \\
$(89 \%)$ & $(57 \%)$ & $(33 \%)$ & \\
\hline
\end{tabular}

Abbreviations: $\quad \mathrm{BT}=$ brachytherapy; $\quad \mathrm{EBRT}=$ external beam radiotherapy; $\mathrm{RP}=$ radical prostatectomy. 
Outcome by treatment modality. Some variations existed within the three types of treatments. Nerve sparing was performed in the majority $(81 \%)$ of the prostatectomy patients. Patients with and without nerve sparing had comparable outcomes; at 12 months after treatment they did not differ significantly on the urinary ( $83 \pm 15$ vs $88 \pm 13$, respectively) or sexual summary scores (30 \pm 17 vs $27 \pm 18$, respectively). No effect was found for the surgery techniques either; open, laparoscopic or robot-assisted laparoscopic surgery yielded urinary summary scores of 85,79 and 83 respectively. The effect of hormonal therapy in combination with radiotherapy was not analysed due to the small number of patients receiving this combined therapy $(n=5)$.

\section{DISCUSSION}

In this study, men were selected to be eligible for both surgery and radiotherapy. This enabled us to compare quality of life effects of different treatments in men more comparable at baseline than in previous studies. The effects on the urinary and sexual domain were in line with earlier reports. A striking result in our study is that the bowel domain was not affected by the treatment received. The bowel problems usually reported after EBRT, were not found in this study.

A possible explanation for the good radiotherapy outcome may be that in our study the EBRT patients were selected to be comparable to the RP patients. As a result, the EBRT patients in our study were relatively young (mean age of 65) compared with those usually studied (mean ages ranging from 64 to 76 (Ferrer et al, 2008; Korfage et al, 2005; Miller et al, 2005; Smith et al, 2009; Wei et al, 2002)). It has been shown that younger men are less prone to treatment-related toxicity than older men (Stanford et al, 2000; Huang et al, 2010). In our study, the patients receiving EBRT showed good bowel scores compared with previous studies. For example, the bowel function score at follow-up was 92, whereas others reported scores from 80 to 85 (Korfage et al, 2005; Smith et al, 2009; Huang et al, 2010). Similarly, the bowel bother score was 94, whereas others reported scores from 75 to 80 (Korfage et al, 2005; Smith et al, 2009; Huang et al, 2010).

The RP patients in our study were comparable to those usually studied, with a mean age of 64 compared with 60-67 reported by others (Wei et al, 2002; Korfage et al, 2005; Miller et al, 2005; Ferrer et al, 2008; Smith et al, 2009). This is reflected by their bowel scores being similar to those mentioned in previous reports, with a bowel function score of 94 vs reports ranging from 88 to 90 , and a bother score of 96 vs reports of 90-93 (Korfage et al, 2005; Smith et al, 2009; Huang et al, 2010).

Another explanation for the good outcomes of the EBRT patients may be the radiation technique that was used; IMRT and applying the endorectal balloon to limit radiation-induced toxicity. This rectal balloon was shown to reduce the dose to the anorectal wall, which may reduce anorectal toxicity (Smeenk et al, 2010). However, to date, no HR-QOL data are available in the literature to validate this assumption.

In all, our data suggest that EBRT causes little damage in men who are comparable to surgery patients and who are irradiated with state-of-the-art techniques, using e.g., IMRT and rectal balloon.

Strengths and limitations. A strength of this study is that the selection succeeded in creating patient groups that were comparable at baseline, both for demographic and tumour characteristics. The groups receiving RP and EBRT were also comparable in their baseline HR-QOL. In addition, the intake of all patients was equal, that is, all patients were enrolled at the Urology departments.

Another strength is that the HR-QOL assessment was based on patient reported outcomes. This is an advantage because patients often don't report all morbidity to their physician. Moreover, when physician and patient assessments are compared, physicians underestimate patients HR-QOL symptoms (Wilson et al, 2000; Sonn et al, 2009).

A limitation of the study is that the patients receiving RP and EBRT were comparable on all accounts, but the group receiving BT had somewhat better urinary scores. The latter is inherent to the selection criteria as commonly applied for BT and yields a patient group representative for the BT group in common clinical practice.

Another limitation is that comorbidity was not assessed. However, patients were only enrolled when eligible for both surgery and radiotherapy, which ruled out comorbidity interfering with treatment choice. In addition, the follow-up of 12 months may be too short to capture the long-term treatment effects. Previous reports on long-term recovery are mixed. Some studies have reported recovery after more than 1 year post-treatment, especially for sexual functioning (Gore et al, 2010; Huang et al, 2010), but most studies found little to no change in urinary and bowel scores (Talcott et al, 2003; Ferrer et al, 2008; Gore et al, 2010) after $>1$ year. In contrast, some studies found a decline in sexual functions after more than 1 year post-treatment in EBRT patients, resulting in smaller differences between RP and EBRT patients in the long term (Potosky et al, 2004; Korfage et al, 2005). This may be related to progressive injury from radiotherapy, but also to the more advanced age in the EBRT groups in those studies.

Treatment groups were unequal in size, and the BT or the EBRT groups were small due to the fact that those treatments were less frequently chosen, reflecting common treatment patterns in the Netherlands. The small sample sizes limit the power of our analyses. Nevertheless, significant results were found. In addition, the treatments were somewhat heterogeneous; prostatectomies were performed by three different procedures with or without nerve sparing, and five patients with EBRT had their treatment combined with hormone deprivation. This, again, is common variation found in clinical practice. The effect of the different prostatectomy techniques was small in our study. This was not surprising, because most studies found no difference in long-term HR-QOL in relation to open, laparoscopic and/or robot-assisted procedures, when analysed by validated instruments (Penson, 2007).

\section{CONCLUSION}

As guidelines nowadays agree that there is no treatment that is superior for survival (Thompson et al, 2007), quality of life effects should be taken into consideration when choosing a treatment. Our results suggest that for patients who actually have a choice, radiotherapy, delivered as EBRT or BT, is at least as good an option as RP in terms of side effects.

Our study provides some indication that the negative effects of EBRT, when applied according to the latest techniques, e.g., with IMRT and rectal balloon, appear to be less pronounced than previously assumed. More research, with longer follow-up, needs to be done to confirm this finding. We recommend that future studies comparing the effects of different treatments should only include patients selected to be eligible for both treatments.

\section{ACKNOWLEDGEMENTS}

Financial support for this study was provided by a grant (20073809) from the Dutch Cancer Society, Amsterdam, The Netherlands. 


\section{REFERENCES}

Crook JM, Gomez-Iturriaga A, Wallace K, Ma C, Fung S, Alibhai S, Jewett M, Fleshner N (2011) Comparison of health-related quality of life 5 years after SPIRIT: Surgical Prostatectomy Versus Interstitial Radiation Intervention Trial. J Clin Oncol 29(4): 362-368.

Ferrer M, Suarez JF, Guedea F, Fernandez P, Macias V, Marino A, Hervas A, Herruzo I, Ortiz MJ, Villavicencio H, Craven-Bratle J, Garin O, Aguilo F (2008) Health-related quality of life 2 years after treatment with radical prostatectomy, prostate brachytherapy, or external beam radiotherapy in patients with clinically localized prostate cancer. Int J Radiat Oncol Biol Phys 72(2): 421-432.

Gore JL, Gollapudi K, Bergman J, Kwan L, Krupski TL, Litwin MS (2010) Correlates of bother following treatment for clinically localized prostate cancer. J Urol 184(4): 1309-1315.

Huang GJ, Sadetsky N, Penson DF (2010) Health related quality of life for men treated for localized prostate cancer with long-term followup. J Urol 183(6): 2206-2212.

Korfage IJ, Essink-Bot ML, Borsboom GJ, Madalinska JB, Kirkels WJ, Habbema JD, Schroder FH, de Koning HJ (2005) Five-year follow-up of health-related quality of life after primary treatment of localized prostate cancer. Int J Cancer 116(2): 291-296.

Liss MA, Osann K, Canvasser N, Chu W, Chang A, Gan J, Li R, Santos R, Skarecky D, Finley DS, Ahlering TE (2010) Continence definition after radical prostatectomy using urinary quality of life: evaluation of patient reported validated questionnaires. J Urol 183(4): 1464-1468.

Madalinska JB, Essink-Bot ML, de Koning HJ, Kirkels WJ, van der Maas PJ, Schroder FH (2001) Health-related quality-of-life effects of radical prostatectomy and primary radiotherapy for screen-detected or clinically diagnosed localized prostate cancer. J Clin Oncol 19(6): 1619-1628.

Miller DC, Sanda MG, Dunn RL, Montie JE, Pimentel H, Sandler HM, McLaughlin WP, Wei JT (2005) Long-term outcomes among localized prostate cancer survivors: health-related quality-of-life changes after radical prostatectomy, external radiation, and brachytherapy. J Clin Oncol 23(12): 2772-2780.

Morton GC, Loblaw DA, Chung H, Tsang G, Sankreacha R, Deabreu A, Zhang L, Mamedov A, Cheung P, Batchelar D, Danjoux C, Szumacher E (2011) Health-related quality of life after single-fraction high-dose-rate brachytherapy and hypofractionated external beam radiotherapy for prostate cancer. Int J Radiat Oncol Biol Phys 80(5): 1299-1305.

Norman GR, Sloan JA, Wyrwich KW (2003) Interpretation of changes in health-related quality of life: the remarkable universality of half a standard deviation. Med Care 41(5): 582-592.

Penson DF (2007) Quality of life after therapy for localized prostate cancer. Cancer J 13(5): 318-326.

Potosky AL, Davis WW, Hoffman RM, Stanford JL, Stephenson RA, Penson DF, Harlan LC (2004) Five-year outcomes after prostatectomy or radiotherapy for prostate cancer: the prostate cancer outcomes study. J Natl Cancer Inst 96(18): 1358-1367.

Smeenk RJ, Teh BS, Butler EB, van Lin EN, Kaanders JH (2010) Is there a role for endorectal balloons in prostate radiotherapy? A systematic review. Radiother Oncol 95(3): 277-282.

Smith DP, King MT, Egger S, Berry MP, Stricker PD, Cozzi P, Ward J, O'Connell DL, Armstrong BK (2009) Quality of life three years after diagnosis of localised prostate cancer: population based cohort study. BMJ 339: b4817.

Sonn GA, Sadetsky N, Presti JC, Litwin MS (2009) Differing perceptions of quality of life in patients with prostate cancer and their doctors. J Urol 182(5): 2296-2302.

Stanford JL, Feng Z, Hamilton AS, Gilliland FD, Stephenson RA, Eley JW, Albertsen PC, Harlan LC, Potosky AL (2000) Urinary and sexual function after radical prostatectomy for clinically localized prostate cancer: the Prostate Cancer Outcomes Study. JAMA 283(3): 354-360.

Talcott JA, Manola J, Clark JA, Kaplan I, Beard CJ, Mitchell SP, Chen RC, O'Leary MP, Kantoff PW, D'Amico AV (2003) Time course and predictors of symptoms after primary prostate cancer therapy. J Clin Oncol 21(21): 3979-3986.

Thompson I, Thrasher JB, Aus G, Burnett AL, Canby-Hagino ED, Cookson MS, D'Amico AV, Dmochowski RR, Eton DT, Forman JD, Goldenberg SL, Hernandez J, Higano CS, Kraus SR, Moul JW, Tangen CM (2007) Guideline for the management of clinically localized prostate cancer: 2007 update. J Urol 177(6): 2106-2131.

van Tol-Geerdink JJ, Leer JW, Weijerman PC, van Oort IM, Vergunst H, van Lin EN, Witjes JA, Stalmeier PF (2013) Choice between prostatectomy and radiotherapy when men are eligible for both: a randomized controlled trial of usual care vs decision aid. BJU Int 111: 564-573.

Wei JT, Dunn RL, Litwin MS, Sandler HM, Sanda MG (2000) Development and validation of the expanded prostate cancer index composite (EPIC) for comprehensive assessment of health-related quality of life in men with prostate cancer. Urology 56(6): 899-905.

Wei JT, Dunn RL, Sandler HM, McLaughlin PW, Montie JE, Litwin MS, Nyquist L, Sanda MG (2002) Comprehensive comparison of health-related quality of life after contemporary therapies for localized prostate cancer. J Clin Oncol 20(2): 557-566.

Wilson KA, Dowling AJ, Abdolell M, Tannock IF (2000) Perception of quality of life by patients, partners and treating physicians. Qual Life Res 9(9): 1041-1052.

This work is published under the standard license to publish agreement. After 12 months the work will become freely available and the license terms will switch to a Creative Commons AttributionNonCommercial-Share Alike 3.0 Unported License. 